\title{
ANÁLISE BIBLIOMÉTRICA DA PRODUÇÃO CIENTÍFICA BRASILEIRA SOBRE JORNALISMO VISUAL ENTRE 2012 E 2018
}

\author{
BIBLIOMETRIC ANALYSIS OF BRAZILIAN SCIENTIFIC PRODUCTION ON VISUAL \\ JOURNALISM BETWEEN 2012 AND 2018
}

\author{
Greice Schneider*, Renata Benia**, Andressa Pedrosa**
}

\begin{abstract}
Resumo
O panorama atual do jornalismo visual aponta não somente para os variados recursos integrantes da composição informacional, mas para uma relação dos protocolos de produção e recepção; sobre como a interação e diálogo entre os elementos visuais podem privilegiar um novo espaço para o agenciamento de leitura e experiências estéticas com a informação. 0 objetivo deste estudo é compreender, a partir da pesquisa bibliométrica, qual é o estado da arte de tal temática nas publicações brasileiras entre 2012 até 2018, e para isso, são abarcadas as produções inseridas em revistas científicas e anais de eventos que versam sobre jornalismo visual, e termos relacionados, como infografia, jornalismo gráfico e multimídia. Constatamos três movimentos no estado da arte; há um pensamento que gira em torno dos recursos multimídia inserido na consideração dos elementos visuais e textuais como elementos que competem entre si; não é o foco desses estudos a abordagem de um caráter emotivo e sensorial do leitor; e não há o enfoque da discussão sobre o uso de fotografia em infográficos. Com este estudo, espera-se corroborar com pesquisas futuras preocupadas com o jornalismo visual, alargando assim o estado da arte desta temática, a partir de um olhar mais profundo sobre as possíveis lacunas, fragilidades, potencialidades e perspectivas no terreno das produções científicas.
\end{abstract}

Palavras-chave: Bibliometria. Infografia. Jornalismo visual. Multimídia.

\begin{abstract}
In addition to pointing to the various resources that are part of the informational composition, visual journalism points to a relation between the production and reception protocols; about how the interaction and dialogue between visual elements can privilege a new space for the agency of reading and aesthetic experiences with information. Based on bibliometric research, the goal of this study is to understand what is the state of the art of such a theme in Brazilian publications in the period between 2012 and 2018. In order to do that, we included productions from scientific journals and annals of events covering visual journalism and related
\end{abstract}

\footnotetext{
* Professora do Programa de Pós-Graduação em Comunicação da Universidade Federal de Sergipe, Doutora em Comunicação pela Katholieke Universiteit Leuven. Membro da RedeGrafo - Rede Integrada de Pesquisa sobre Teorias e Análise da Fotografia e Coordenadora do LAVINT - Laboratório de Análise de Visualidades, Narrativas e Tecnologias. E-mail: greices@gmail.com.

${ }^{* *}$ Bolsista CAPES no Mestrado em Comunicação pela Universidade Federal de Sergipe - UFS. Membro do Grupo de Pesquisas LAVINT - Laboratório de Análise de Visualidades, Narrativas e Tecnologias (UFS) e da RedeGrafo - Rede Integrada de Pesquisa sobre Teorias e Análise da Fotografia. E-mail: renatabenia@gmail.com.

*** Estudante de Graduação, $7^{\circ}$ semestre do curso de Comunicação com habilitação em Jornalismo na Universidade Federal de Sergipe - UFS. Bolsista voluntária de Iniciação Científica PICVOL/COPES na Universidade Federal de Sergipe - UFS. E-mail: charlotte.borges2@gmail.com.
} 
terms, such as infographics, graphic journalism and multimedia journalism. We found three movements in the state of the art; there is a thought that revolves around multimedia resources inserted in the consideration of visual and textual elements as competing elements; it is not the focus of these studies to approach the reader's emotional and sensory character; and there is no focus on the discussion on the use of photography in infographics. Based on the bibliometric research, this study is concerned with understanding the state of the art in Brazilian publications from 2012 to 2018, and for that, will be considered the productions inserted in scientific journals and annals of events that discuss about infographics, visual journalism, graphic journalism and multimedia. With this study, we hope to corroborate future researches concerned with visual journalism, extending the state of the art of this theme, from a deeper look at possible gaps, weaknesses, potentialities and perspectives in the field of scientific productions.

Keywords: Bibliometry. Infographic. Visual journalism. Multimedia.

\section{Datas de submissão e aprovação do artigo}

Submissão: $17 / 6 / 2019$

Aceito: $19 / 8 / 2020$

\section{INTRODUÇÃO}

Este estudo bibliométrico ${ }^{1}$ propõe o exame do estado da arte das pesquisas sobre jornalismo visual no Brasil através do mapeamento da produção intelectual endereçada a tal temática. Neste sentido, permeando o terreno do jornalismo visual e suas instâncias, tais como infografia, jornalismo gráfico e multimídia, este estudo pretende realizar o levantamento das produções de artigos científicos que se ocupam com o debate de tais questões.

Entendemos jornalismo visual como aquele que produz "imagens produzidas com o compromisso de transmitir informações oportunas e confiáveis apuradas por jornalistas para um público espectador" (HILL; SCHWARZ, 2015, p.4) ${ }^{2}$. Um primeiro desafio para realizar uma análise bibliográfica que contemple as diversas e distintas instâncias de visualidades no jornalismo é o fato de que a eleição de uma só palavrachave jornalismo visual, deixaria escapar uma série de fenômenos envolvidos neste

\footnotetext{
${ }^{1}$ Este estudo deriva do projeto de pesquisa sobre jornalismo visual a partir do exame de produções jornalísticas multimodais desenvolvido entre os anos de 2017 a 2018. As autoras Renata Benia e Andressa Pedrosa se dedicaram a tal pesquisa na Iniciação Científica, na Universidade Federal de Sergipe, sob orientação de Greice Schneider. A pesquisa objetivava ampliar o debate em torno do jornalismo visual a partir do exame de produções jornalísticas multimodais (compreendendo infografias, por exemplo) para assentar as bases das reflexões sobre os novos protocolos de produção e recepção de tais materiais. O projeto abarcou duas etapas; estudo de caso de grandes reportagens, e pesquisa bibliométrica.

2 "(...) images crafted with a commitment to transmit timely and reliable information held by journalists to be of consequence to a viewing public" (HILL; SCHWARZ, 2015, p.4).
} 
termo guarda-chuva que incluem visualidade e jornalismo e que nem sempre são nomeadas como tal. ${ }^{3}$

Ao que toca tal análise, o seu início é datado no período de 17 de agosto a 12 de abril de 2019. O seu recorte, portanto, permeia o período de 2012 a 2018, com o foco dirigido para as publicações feitas em revistas científicas e anais de eventos no terreno científico brasileiro, e, por conseguinte, esta fase de coleta nos levou ao resultado de 110 artigos ao exame proposto. Isso posto, a condução deste exame contempla alguns critérios, a saber: revista ou anais onde fora publicado; quantas vezes foi citado; autores destes artigos; palavras-chave; referências utilizadas.

Através de tais diretrizes levantadas na análise da literatura, buscamos incluir também aqueles artigos que contemplam fenômenos centrais ao jornalismo visual, embora não necessariamente utilizem tal denominação, a saber: infografia, multimídia e jornalismo gráfico. Mesmo que se tratem de conceitos bastante distintos entre si, sua inclusão foi pensada para evitar que ficassem de fora do corpus trabalhos que tratassem de instâncias específicas do jornalismo visual. No horizonte de nossa investigação preliminar, encontramos artigos que ao tratarem da problemática do jornalismo visual, focalizam em suas discussões a reflexão sobre infografia, jornalismo visual, jornalismo gráfico e multimídia. Portanto, acabamos por considerar estes termos como palavras-chave para a nossa busca por produções científicas em torno deste eixo.

0 ponto de partida deste estudo bibliométrico é guiado por algumas questões de fundo, a saber: compreender quais são os novos e iminentes diálogos propostos neste terreno e quais os principais métodos de pesquisa abordados. As questões aqui embasadas voltam-se para o seguinte problema: como as produções acadêmicas vêm tratando tais objetos no contexto do jornalismo visual, de modo que possa ser revelado um diagnóstico das principais tendências e fragilidades no que diz respeito à visualidade da informação no eixo jornalístico?

Com isso, será possível delinear um exame a respeito das possíveis lacunas identificadas em pesquisas e problemas pouco explorados no jornalismo visual. Sob um viés diacrônico, o presente estudo se propõe a oferecer um breve panorama da organização das pesquisas ao longo do recorte abarcado nos últimos seis anos, a fim de perceber as transformações ocorridas, as tendências, bem como as consequências implicadas a partir do diálogo das produções no cenário científico brasileiro. Além disso, pretende-se colaborar com possíveis caminhos metodológicos e teóricos voltados para a compreensão e consolidação destes objetos.

O exercício bibliométrico proposto considera como recorte, periódicos e anais de eventos, de maneira a ter acesso a um leque maior de averiguação das produções tanto em nível de graduação quanto de pós-graduação do Brasil. Tendo em vista a carência de estudos bibliométricos preocupados com o jornalismo visual, manifestase aqui $o$ interesse em contribuir para novas pesquisas a melhor avaliarem o desenvolvimento das investigações desses estudos, quais produções mais relevantes, quais obras mais referenciadas como fonte, quais possíveis lacunas, bem como

\footnotetext{
${ }^{3}$ Também interessa explicar os termos fotojornalismo e jornalismo audiovisual não são abarcados no levantamento, pois compreende-se tais práticas como aquelas que demarcam maior ênfase para um elemento; no primeiro caso, fotografia; no segundo caso, imagem e som. Ao considerarmos o jornalismo visual, jornalismo gráfico, infografia e multimídia, estamos contemplando o regime visual e textual - enquanto elementos que se complementam - como bases da experiência do leitor.
} 
adquirir um olhar mais profundo sobre os trabalhos que vêm sendo produzidos nos últimos anos.

\section{JORNALISMO VISUAL}

O pensamento que cerca o funcionamento do jornalismo visual recai sobre o protagonismo da imagem, mas o que se considera vai muito além dessa atuação isolada.

As imagens de imprensa - ou simplesmente, aquelas imagens que relatam na órbita do jornalismo - são baseadas na difícil ideia e no desejo de que a imediaticidade de uma imagem e sua capacidade de condensar e concretizar o conhecimento possam oferecer a seu espectador uma relação privilegiada com um mundo que de outra forma seria desconhecido ${ }^{4}$ (HILL; SCHWARZ, 2015, p.2, tradução nossa).

A visualização da informação é uma preocupação cada vez mais acentuada, especialmente após a virada imagética (MITCHELL, 2008) tendo em vista o cenário comunicacional saturado de informações que passam despercebidas ou não compreendidas - a depender do conteúdo complexo, volume informacional, e ainda, em função da mudança dos protocolos de leitura e velocidade de produção e circulação da informação. É válido pensar que "muitas ideias [...] são lidas em palavras, entretanto muitas se apreendem pela concisão imagética e até pelo estilo das imagens" (DE SOUZA, 2016, p. 204) e, neste sentido, requisita-se formas de disponibilizar a notícia que convidem a um exercício mais imersivo através da compreensão da informação e experiência sensorial e emotiva. É por isso que, no eixo do jornalismo visual, existe uma proposta decisiva que é a das produções multimodais garantirem a clareza da informação ao mesmo tempo em que propõe um novo tipo de experimentação estética com a notícia (RITCHIN, 2013).

A trajetória dos infográficos tem suas raízes demarcadas em práticas visuais anteriores, como por exemplo na pintura. Sobre sua origem e evolução, é possível identificar duas perspectivas históricas que tentam explicar a origem da infografia: uma perspectiva defende que as primeiras pinturas rupestres poderiam ser consideradas infográficos, pois através dos símbolos os ancestrais realizam o ato comunicativo (SANCHO, 2011) e antes do surgimento da fala e escrita, os ancestrais do homem já transmitiam mensagens utilizando traços (PELTZER, 1991); e por outro lado, a outra assinala que a infografia aparece como expressão nos meios de comunicação a partir dos avanços tecnológicos (CIRNE, 2010).

O fato é que as representações gráficas ao longo da história já buscavam trabalhar a relação mútua entre imagem e conceitos informativos, e com isso, organizar a informação a ser transmitida no processo comunicativo.

\footnotetext{
${ }^{4}$ News pictures-simply, those pictures that report within the orbit of journalism-are predicated upon the difficult idea and desire that a picture's immediacy and ability to condense and concretize knowledge might offer its viewer a privileged relationship to an otherwise unknowable world. (HILL; SCHWARZ, 2015, p.2)
} 
Devido a esse suposto processo cultural, as mensagens antigas que encontramos hoje do antigo Egito e de outros povos históricos são formadas por um binômio de texto e imagem. As paredes dos templos egípcios e as placas de tantos papiros desenhados são um casamento de uma série de sinais com significado literário e uma segunda série de desenhos que dizem a mesma coisa que podem ser lidos no texto, mas em um formato diferente e muito mais visual. (...) Nasceu o infográfico, que não é de forma alguma um produto da era do computador, mas sim o resultado do desejo da humanidade de se comunicar melhor, de tornar mais precisas aquelas primeiras formas de comunicação. 0 infográfico, então, é de hoje, mas também é de ontem, de um ontem bastante remoto. (DE PABLOS, 1998, p. 1-2, tradução nossa) $)^{5}$.

O propósito da comunicação acompanhada pela evolução de tais práticas representativas caminhou por diversos meios até então chegarmos no Jornalismo. A infografia, portanto, deriva de práticas anteriores e se constitui hoje, entre outras coisas, como uma das instâncias do jornalismo visual.

Diante deste quadro histórico, no nosso entendimento, a concepção de um jornalismo visual que contempla a relação de complementaridade entre imagens e textos no relevo jornalístico (em especial, quando se alude aos infográficos) nasce das práticas do Pictorial Journalism (tradição na qual a utilização da imagem era direcionada como mera ilustração da notícia). Foi no Pictorial Journalism onde a infografia como conhecemos hoje nasceu, no momento em que se utilizavam desenhos com finalidade de acompanhamento e ilustração da notícia (RODRIGUES; BIERNATH, 2015).

No nosso entendimento, consideramos que a proposta basilar era justamente de ancoragem ${ }^{6}$, não se reverenciava a compreensão das informações; a preocupação primária era instalar um aspecto visualmente mais impactante e belo à notícia (CASADEI; RODRIGUES; BIERNATH, 2016). O apogeu da infografia se revelou quando houve uma mudança de vetor em relação ao tratamento e disseminação da notícia (entre os anos 80 e 90):

A necessidade de tornar os jornais mais atraentes - em função da nova cultura da imagem (...) popularização da televisão e a perda de

\footnotetext{
${ }^{5}$ Por este supuesto proceso cultural, los mensajes antiguos que hoy encontramos del viejo Egipto y de otros pueblos históricos están formados por un binomio de texto e imagen. Las paredes de los templos egipcios y las láminas de tantos papiros dibujados son un matrimonio de una serie de signos con significado literario y una segunda serie de dibujos que están diciendo lo mismo que se puede leer en el texto, pero en un formato diferente y más visual. (...) Había nacido la infografía, que no es en modo alguno un producto de la era informática, sino fruto de los deseos de la humanidad por comunicarse mejor, por dejar más acuradas aquellas primeras formas de comunicar. La infografía, pues, es de hoy, pero también lo es de ayer, de un ayer bastante remoto. (DE PABLOS, 1998, p. 1-2).

${ }^{6} \mathrm{~A}$ ancoragem trata-se de um termo elencado por Barthes (1990) para tratar da relação entre imagem e texto na mensagem fotográfica. 0 termo diz respeito a uma relação na qual o texto vem a cristalizar determinado sentido à imagem de uma maneira que impeça o leitor de vislumbrar outros possíveis sentidos. Induz-se, portanto, um sentido pré-estabelecido ao passo em que leva o sujeito a abandonar outros tangenciados.
} 
leitores - fez com que novas alternativas fossem buscadas (...) informatização das redações e o avanço dos recursos de impressão também contribuíram para o gradual aumento do uso de infografias. (ibidem, p. 107).

Parece conveniente ainda destacar que o cenário do jornalismo visual ganhou maior expressividade justamente em decorrência do regime visual e das novas práticas do olhar e fruição do observador com os produtos (visuais, sobretudo) com caráter de mensagem ou sensorial. Esse regime do olhar chama atenção para determinadas marcas ainda existentes no campo do jornalismo visual que são oriundas do jornalismo de precisão. Conforme aponta Casadei, Rodrigues e Biernath (2016), a década de 60 foi o momento no qual a utilização de bases de dados numéricos no jornalismo ganhou mais recorrência. Esse exercício guarda a discussão sobre a objetividade no jornalismo contornada pela crença e esforços recaídos sob uma 'fiel' retratação do fato como uma promessa de pacto com o leitor.

Nesse sentido, existe uma inclinação à validação de dados e efeito de credibilidade, justamente a partir do momento em que se trata o jornalismo como uma ciência ao se adotar o discurso de um método científico prezando pela objetividade. Mas é sabido que, embora se lapide sob um ideal objetivo, as narrativas jornalísticas abrem perspectiva para construções complexas, que envolvam o destrave do sensível e espaço para polissemia no agenciamento de leitura, em especial, no alicerce das produções multimodais e visuais. ${ }^{7}$

\section{ANÁLISE DOS DADOS}

Tendo em vista o objetivo deste estudo, a análise é amparada na abordagem quantitativa, mas também qualitativa por meio do exame de artigos que versem sobre temas caros ao jornalismo visual. No período de 17 de agosto a 12 de abril de 2019, foram coletados 110 artigos publicados nos anos de 2012 a 2018, contemplando alguns critérios erguidos para tal análise, a saber: revista ou anais onde fora publicado, quantas vezes foi citado, autores destes artigos, palavras-chave, referências utilizadas. Tais critérios abrem espaço para um olhar mais profundo voltado para as abordagens que estão sendo feitas sobre os objetos situados a fim de que seja possível revelar o que vem sendo produzido e explorado em questões teóricas e metodológicas.

0 ponto de partida deste estudo foi marcado por leituras basilares consideradas essenciais na área que cerca o objeto. Essa seleção foi proposta a partir do levantamento bibliográfico erguido que buscava traçar um exame sobre as produções científicas que se ocupam de questões caras ao jornalismo visual. Além de esse exame ter sido oportuno para firmar o diagnóstico sobre o estado da arte, também foi valioso para conceber bases bibliográficas decisivas e leituras basilares

\footnotetext{
${ }^{7}$ Embora fosse utilizado de modo mais corriqueiro com dados quantitativos e ainda que o jornalismo de dados encontre nos infográficos um terreno fértil para a representação visual da informação, cabe lembrar que infográficos são heranças de outras representações já efetivadas a partir de esquemas menos sofisticados, para além da ênfase meramente quantitativa (1801, pelo The Times; esquema de uma batalha naval entre a frota inglesa e a dinamarquesa e 1806; primeiro infográfico publicado intitulado Mr. Blights House).
} 
no campo (CAIRO, 2006, MANOVICH, 2011).

Após essa fase exploratória, dirigiu-se para o momento do exercício bibliométrico. Buscou-se selecionar os artigos a partir das palavras-chave que se localizam na esfera do jornalismo visual (considerando a mútua relação entre imagem e texto como programadores de efeitos e compreensão da informação). Para tanto, considera-se como recorte periódicos e anais de eventos consultados na base do Google Scholar, de maneira a ter acesso a um leque maior de averiguação das produções tanto em nível de graduação quanto de pós-graduação. O levantamento foi arquitetado sob alguns critérios valiosos para refinar o processo de busca e de análise. Delimitou-se um recorte entre 2012 e 2017. Ao passo em que a coleta dos artigos foi efetuada, foram identificados: os títulos do artigo; , o periódico em que foi publicado o artigo; os autores; as palavras-chave; quantas vezes o referido artigo foi citado por outros; e as referências que são utilizadas.

Em um segundo momento, após a coleta ser realizada, uma tabela foi construída com o propósito de alinhar e tabular os dados coletados. Após este momento, direcionou-se para a leitura e análise dos artigos coletados. Esse exercício de leitura apoiou-se a partir da seleção das produções mais citadas em cada ano da coleta, bem como das produções mais citadas no geral.

A fim de melhor compreender este cenário em transformação, em especial, aos seus aspectos históricos, metodológicos, discursivos, imagéticos, sob essa perspectiva, foi realizada a leitura de obras mais citadas em tais produções, e então, pôde-se esbarrar em textos essenciais (De Pablos, Manovich, Cairo etc.), e que, configuram-se como leitura base para identificar o estado da arte em questão. No decorrer deste desdobramento, a pesquisa se concentrou na análise dos dados a partir do cruzamento dos dados coletados, sendo estes ilustrados no horizonte da discussão a seguir.

Em linhas gerais, ao que concerne o jornalismo visual e suas questões mais particulares, aponta-se para a abordagem não somente no campo da comunicação no terreno do jornalismo, mas, sobretudo, no campo do design. Um exemplo bastante evidente desse cenário se concentra nos espaços de publicações; nas revistas e anais científicos. Aqui convém apontar que o recorte não contém exclusivamente produções de periódicos científicos, mas alcança-se também os anais de eventos que se ocupam com a discussão sobre o objeto contemplado nesta pesquisa.

Ao adicionar os anais de eventos como um local de publicação oportuno ao exame proposto, vislumbra-se um horizonte mais amplo em torno das discussões englobadas sobre jornalismo visual. Tais bases de dados auxiliam no entendimento sobre o desenvolvimento de tais produções tanto a nível de graduação, quanto de pós-graduação, permitindo um olhar que entenda as incidências destes debates em tais campos e quais suas propostas. Tendo em vista o reconhecimento de haver a possibilidade de variedade de estudos localizados em tais anais, preferiu-se ampliar o leque do recorte a fim de explorar produções no terreno da graduação igualmente. O Intercom - Congresso Brasileiro de Ciências da Comunicação é protagonista quando se averigua o lugar onde mais se publicou estudos.

A natureza destas produções realçava ênfase para produções laboratoriais realizadas pelos próprios estudantes ao nível de graduação, bem como se preocupavam com questões que versavam sobre as práticas e movimentos mercadológicos. Isto é, a ênfase recai sobre a prática, processos e rotina do 
jornalismo visual em mídias, para além das discussões desenhadas num quadro teórico. Já em 2018, essa tendência foi sendo menos expressiva, uma vez que a maioria dos estudos é concentrada em revistas, produzidas por estudantes da pósgraduação (e fora do recorte analisado, é interessante destacar que houve um aumento do número de dissertações e teses a respeito de infografias e jornalismo visual).

As produções seguem a versar sobre rotinas produtivas, estudos de casos comparativos e objetivos propositivos observados em portais jornalísticos ou revistas, contudo, com uma menor concentração (se levado em conta os anos anteriores do recorte analisado). Se dedicam, neste sentido, às propostas mais teóricas a respeito do jornalismo, ancoradas nos modos de produção e contextos sociais, históricos e culturais.

Quadro 1 - Nível de autoria, local de publicação e discussões das publicações.

\begin{tabular}{|c|c|c|c|}
\hline Período & Nível & Base de dados & Discussões \\
\hline $2012-2017$ & Graduação & Anais de Eventos & $\begin{array}{c}\text { pesquisas experimentais, } \\
\text { processos, rotinas, práticas e } \\
\text { discussões mercadológicas. }\end{array}$ \\
\hline 2018 & Pós-graduação & Revistas Científicas & $\begin{array}{c}\text { propostas teóricas, modos de } \\
\text { produção, contextos sociais, } \\
\text { históricos e culturais. }\end{array}$ \\
\hline
\end{tabular}

Fonte: as autoras (2019)

A análise, portanto, despertou a observação esperada de que as produções interessadas em tratar infográficos - por exemplo - não apenas residem em periódicos de jornalismo, mas também estão localizados na área do design. Sinalizase aqui um movimento no qual encontra o eixo interdisciplinar como um dos métodos de abordagem. Parece conveniente citar a Revista brasileira de Design da Informação, um dos três periódicos que mais concentravam publicações em torno da temática apontada neste estudo. Essa recorrência sinaliza um movimento no qual o jornalismo visual é contemplado nas preocupações do design, em especial, ao que toca as infografias e suas composições. E, diante desse panorama, os Anais do Intercom e a revista Brazilian Journalism Research (com o artigo "A Infografia Multimídia como Narrativa Jornalística e as Possibilidades do HTML5" de Walter Teixeira Lima Junior e Eduardo Fernando Uliana Barboza, publicado em 2015, vinte e nove vezes citados refletindo uma posição de destaque).

Estes autores, em coincidência, acabam por amparar seus pressupostos em bases bastante similares. Fala-se aqui de autores que são consagrados a respeito dos temas contemplados, como infografia e jornalismo (os assuntos centrais na maioria das produções). De acordo com o exame levantado na análise, evidencia-se que Cairo, Sancho e De Pablos, (cujas produções são como uma espécie de alicerce para o desenvolvimento das questões práticas e reflexivas sobre infografias), são os autores mais citados das 110 produções tomadas na análise.

Quando voltamos o olhar para fontes brasileiras, o vetor se inclina para um 
movimento novo. Se nos anos de 2012 a 2017 tínhamos mais pesquisadores brasileiros referenciados nas pesquisas, tais como Santaella e Lemos (conduzidos na maioria dos estudos para discutir sobre a convergência dos meios, sobre o terreno da cibercultura, do desenvolvimento do jornalismo visual dentro de um cenário restrito aos dispositivos e tecnologias), no último ano, 2018, houve uma mudança notável em torno dessas abordagens teóricas.

Gráfico 1 - Autores mais citados como referências em artigos que tratam sobre jornalismo visual entre 2012 - 2017.

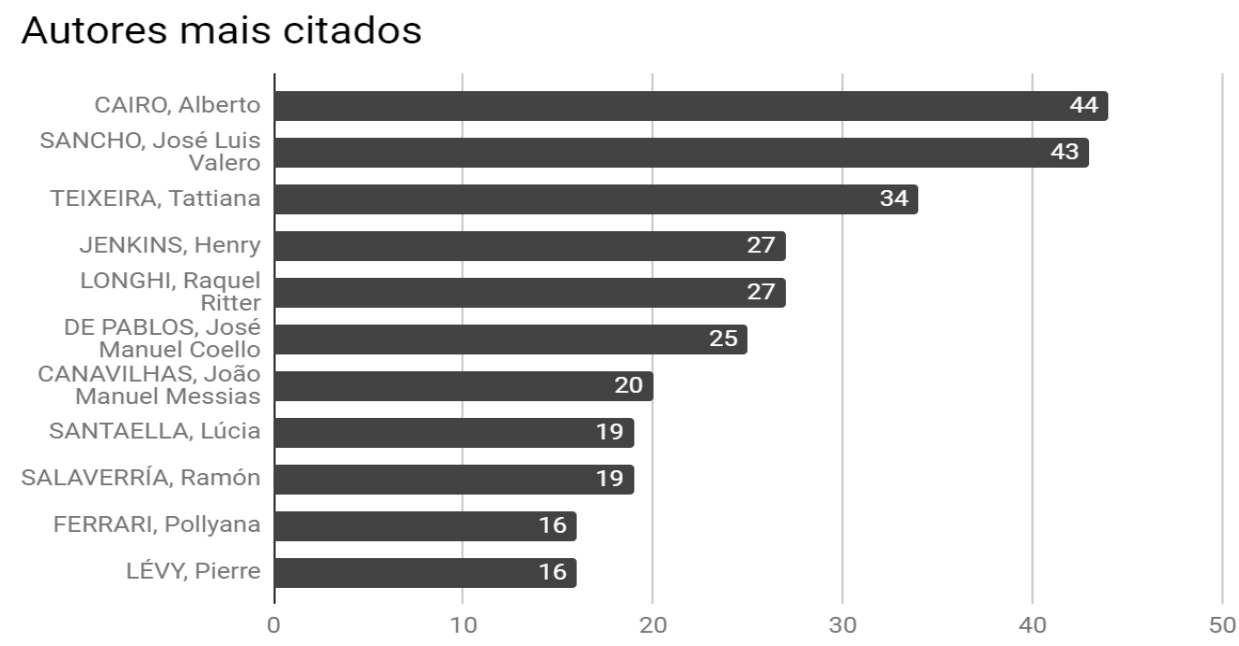

Fonte: as autoras (2019)

Implica falar de três perspectivas de mudança: áreas de conhecimento; linhas de pesquisa; os objetivos destes estudos publicados no ano mais recente (2018); e certo amadurecimento do estudo sobre jornalismo visual no Brasil, com o aumento de publicações em revistas científicas (em especial nas teses e dissertações neste ano em relação aos anteriores).

Nos últimos 5 anos (2012-2017), a predominância, conforme dito, era de autores próprios do campo da cibercultura adotados para referenciar os diálogos e pressupostos dos estudos. Já no ano passado, com a área de conhecimento mais voltada para o jornalismo, pouco distante do foco da cibercultura e convergência, boa parte das pesquisas se debruçam sobre a reflexão desse jornalismo visual, contemplando o cenário histórico, social e cultural onde suas práticas incidem e florescem. Raquel Longhi passa a ser uma das autoras mais citadas em referências dos textos publicados, e isso é um sinal justamente do aumento dessas discussões vislumbradas sob um novo contorno, sobre um terreno mais calcado na perspectiva histórica e teórica concernente ao jornalismo visual.

Sob essa perspectiva de autoria, observa-se que existem algumas lacunas, implicando num juízo de que existe um terreno ainda pouco explorado e escorregadio, no âmbito da apuração dos dados referente às representações de 
infográficos (analisado apenas como um complemento visual da informação e uma análise meramente descritiva da imagem), texto e imagem. Tal fato rompe com o caráter inovador de um olhar mais profundo e completo para tais objetos contemporâneos.

Esse cenário convida à reflexão sobre quais as abordagens metodológicas e temáticas que os estudos se comprometem a discutir. As técnicas quantitativas e qualitativas oferecem um olhar mais claro sobre o desenvolvimento da literatura acadêmica a respeito do objeto, bem como, encaminhar o leitor para publicações influentes e possíveis lacunas na pesquisa. Ao que tangencia tal abordagem dentro das produções acadêmicas dedicadas ao exame do estado da arte sobre o jornalismo visual, Aussiehofer (2017) chama a atenção, especialmente, para o processo e o produto como sendo principais focos de análise onde “(...) algumas definições enfatizam a mudança no processo e no produto (...) Outras definições realçam que o jornalismo de dados produz novos itens baseados em análise de dados (...)". (AUSSIEHOFER, 2017, p. 4, tradução nossa). ${ }^{8}$

É valioso notar que a maioria das pesquisas se interessam em olhar o seu objeto e examiná-lo sob a égide da abordagem qualitativa, representando $75 \%$ das publicações (preocupada com tipologias e questões teóricas e de processo), ao passo em que as demais produções que contemplavam o método quantitativo inclinava-se para um terreno contornado pela análise de conteúdo de produtos criados pela mídia ou laboratoriais. Nos primeiros anos de análise (em especial de 2012 a 2016) constatou-se uma ênfase para questões históricas, teóricas e processuais, já em 2017, por sua vez, privilegia-se a análise de conteúdo como um dos principais métodos para a discussão do jornalismo visual. Em 2018, verificamos um número menor destas abordagens e interesses, já que a maioria se dirige a lançar um olhar sobre questões puramente históricas, teóricas, contudo, ainda propositivas, experimentais e com certo foco para estudos de casos igualmente (embora com menor incidência, se comparado aos anos anteriores).

Sob realce de um panorama geral, é notório observar que há uma recorrência baixa de produções preocupadas com o debate do jornalismo visual. Essa constatação se dá a partir da mudança dos termos em alguns anos da análise. O número total de artigos coletados no recorte contemplado nesta análise foi de 110 artigos desde 2012 até 2018. E esse número se torna ainda menos expressivo quando lançamos o foco para os dois últimos anos (2012 - 9 artigos, 2013 - 16 artigos, 2014 - 20 artigos, 2015 - 24 artigos, 2016 - 15 artigos, 2017 - 8 artigos, 2018 - 18 artigos) (ver Gráfico 2).

Em 2016 e 2017, nota-se uma redução do número de estudos publicados nos anais de eventos e revistas, ao passo em que no ano passado, este número aumenta de 15 artigos lançados em 2016, 8 artigos no ano de 2017, para 18 artigos em 2018. Ao mesmo tempo, convém assinalar que há uma mudança no aumento do número de produções, em 2018, revelando uma preocupação maior com as questões envoltas ao jornalismo visual.

8 "(...) some definitions focus on the change in the process and product (...) Other definitions emphasize that data journalism produces news items based on data analysis (...)". (AUSSIEHOFER, 2017, p. 4, grifo nosso). 
Gráfico 2 - Artigos publicados anualmente

\section{NÚMERO DE ARTIGOS PUBLICADOS}

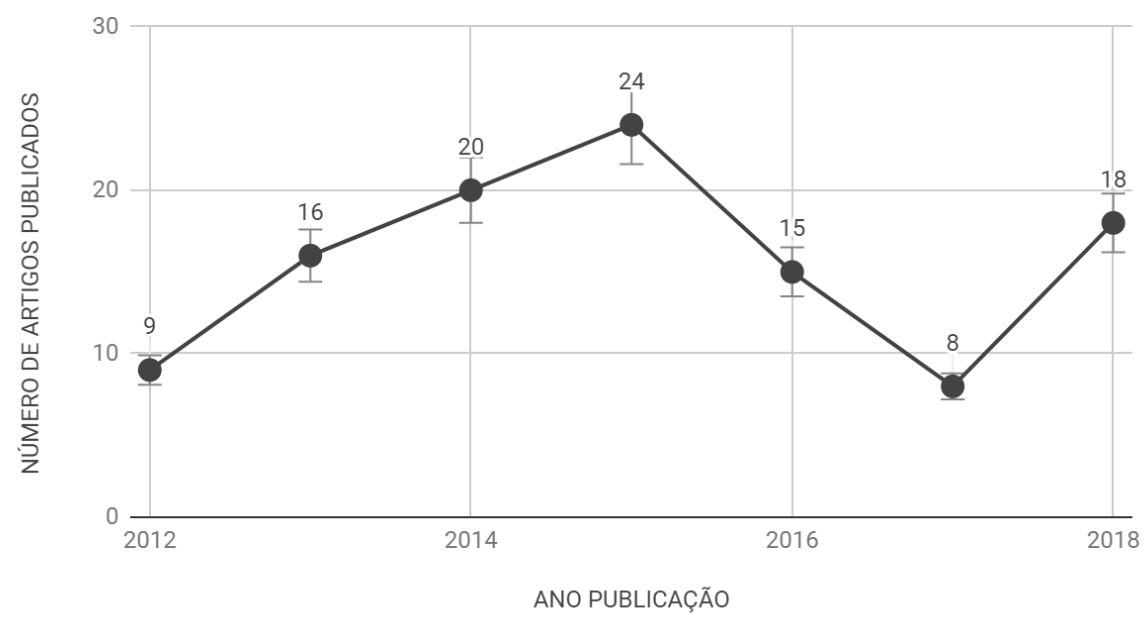

Fonte: as autoras (2019)

Seria possível levantar a hipótese de que a diminuição das produções em 2017 e 2018 pudesse ser explicada a partir de um movimento de atualização dos assuntos das pesquisas. Inicialmente, com a calorosa abordagem em torno do percurso histórico, origem, definições, processos reverenciava-se, assim, a revisão bibliográfica como principal caminho para assentar as bases dos estudos. Por outro lado, ao decorrer dos anos, e com as práticas do jornalismo visual se consolidando e novos problemas surgindo (teóricos e práticos), pede-se um olhar diferente, que dê conta, agora, de problemas desprendidos das questões teóricas, mas resididos nos produtos culturais difundidos pela mídia, nos protocolos de produção, de fato. Afasta-se das noções teóricas, mas elas seguem sendo o pressuposto destes estudos, de modo que o número de produções passa a ser reduzido, posto que muitos problemas já teriam sido esclarecidos, novos termos atualizados e novos problemas despertados no bojo jornalístico e acadêmico.

Ainda ao que concerne o foco dos estudos, verifica-se que boa parte dos estudos publicados dedica-se menos ao uso da fotografia em infográficos, às questões de teoria, visual e regime de percepção e leitura. A predominância dos estudos direcionados às tipologias de infográficos, por exemplo, derivam de periódicos da área do design, e em muitos casos examinados, tratam os processos e rotinas de criação de infográficos como algo inaugural e, portanto, exclusivo a tal atividade, mas que, em realidade, o "molde" sugerido é aplicável e lapidado sob outras atividades que solicitam planejamentos (pesquisa, levantamento, referências, análise, revisão, disseminação).

A razão que explica essa tendência tem uma relação próxima com as temáticas que são mais abordadas nos artigos; é possível verificar que a maioria dos textos se ocupa em discutir sobre infografia (de modo geral e em cada ano consecutivo), tomando a frente de multimídia, por exemplo, que, embora seja a quarta palavra- 
chave mais pontuada; jornalismo multimídia - 5x e multimídia (mas no terreno do jornalismo) - contemplada 9x (ver Gráfico 3).

Gráfico 3 - Palavras-chave mais utilizadas nas publicações que tratam sobre jornalismo visual entre 2012-2018.

\section{5 palavras-chave mais utilizadas}

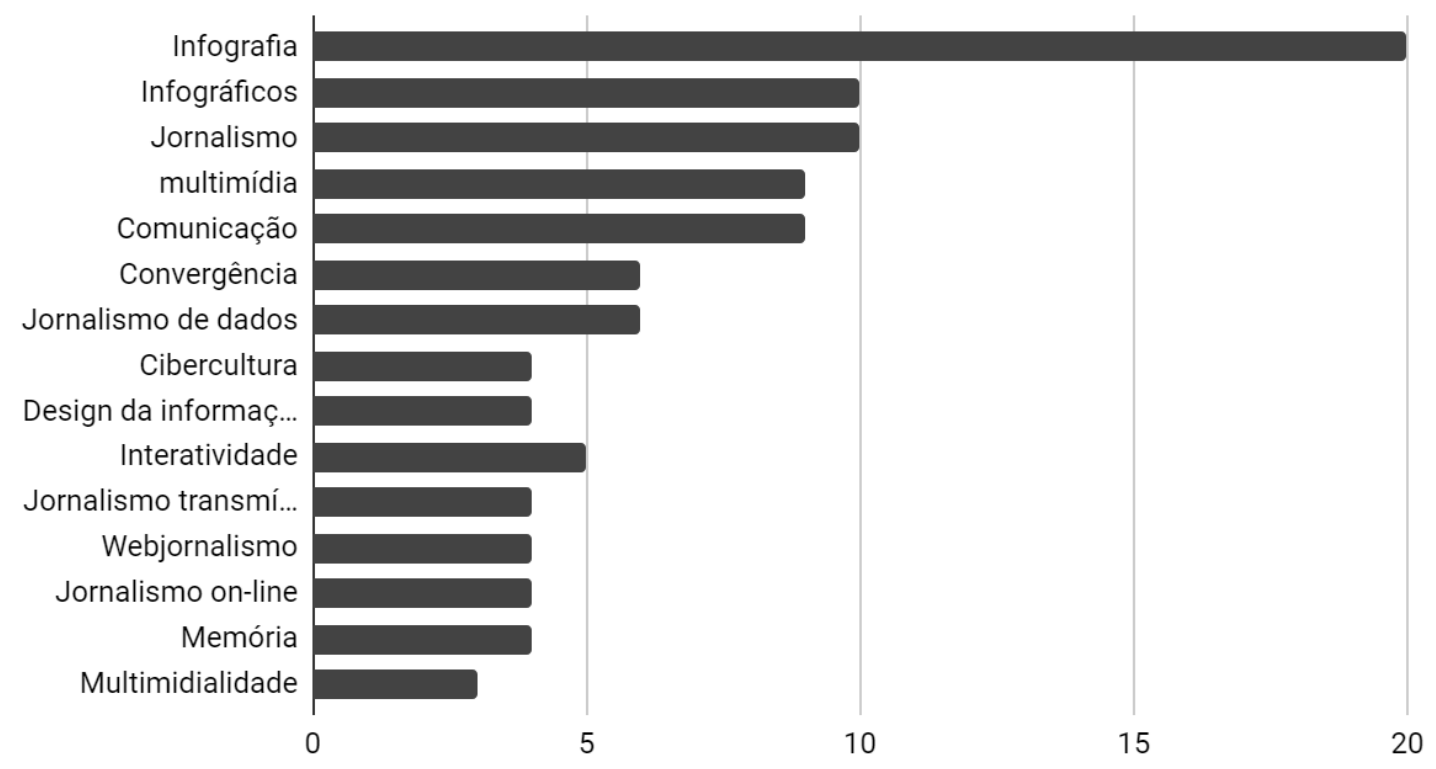

Fonte: as autoras (2019)

Tendo em vista as discussões de análise dessas produções, percebe-se que "rotinas produtivas", "teoria", "tipologia" e "análises comparativas" são os principais eixos focais dos artigos coletados. Diferentemente do que ocorre nos anteriores de 2012 a 2017, as questões voltadas para hipermídia e mobilidade passam a florescer mais recentemente, em 2018. No entanto, há certa tendência, conforme levantamento efetuado, de muitas pesquisas apoiarem-se em estudos de casos (por vezes do mesmo caso) contornando um viés de análises comparativas ou técnicas.

Ainda são evidenciadas questões sobre os modos como consumimos informação, que seja em função da visualização dos dados, na maneira de navegação proposta pelo layout, a maneira como opera a disseminação, as formas e conteúdos dos materiais, quem é o leitor da informação, quais maneiras de engajar e manter o leitor, e os protocolos de criação são algumas perspectivas abraçadas em torno dos estudos.

O contato com o estudo levantado por Ausserhofeer (2017) - ainda que demarque a particularidade de um local específico com outras realidades e problemáticas que não são do Brasil - é decisivo para ampliar o reconhecimento deste cenário que aqui se desenha, na medida em que coincide com os argumentos e constatações erguidos. O que se ressalta na pesquisa bibliométrica acerca das produções acadêmicas concentradas no jornalismo visual mundialmente 
(especialmente na América do Norte e Europa), conforme lembra o autor (2017), é que, por se tratar de um objeto que passa a contornar novas discussões hoje, ainda há um foco para o processo e produto, menos focalizado em examinar lacunas teóricas em quadros metodológicos ao que compete o referido objeto.

Esse relevo examinado abre perspectivas para refletir sobre 0 desenvolvimento destes estudos. As primeiras publicações celebravam questões relativas ao modo como jornalistas usavam diferentes tecnologias computacionais nas rotinas produtivas (DAVENPORT e outros, 1996, 2000; GARRISON, 1999 citado por AUSSERHOFEER, 2017), tal como aos processos tecnológicos, uma vez que:

(...) o crescimento rápido do número e da variedade de projetos de visualização (...) desde o final dos anos 1990, foi possível graças aos avanços da capacidade gráfica dos computadores pessoais, incluindo tanto hardware (...) quanto software (...). (MANOVICH, 2011, p. 159).

Este movimento ainda é aplicado nas publicações mais recentes, sobretudo naquelas onde a área de estudo é voltada para convergência dos meios midiáticos e cibercultura (tratando a visualidade da informação e recepção da informação visual no cerne do dispositivo tecnológico no cenário das TICs). Atribui-se às tecnologias o papel transformador das práticas de visualização dentro do novo regime de visualidade, de modo a deixar escapar questões essenciais referentes a um novo exercício do olhar e de consumo da informação que diz muito mais sobre os contratos de leitura, etapas de produção da mensagem e relações entre diferentes gramáticas. Não é sobre o dispositivo, mas sobre o novo regime visual, como se produz, quais narrativas e quais esquemas contemplados na produção da informação.

\section{CONSIDERAÇÕES FINAIS}

O diagnóstico erguido por este estudo revelou alguns impasses no jornalismo visual a partir do exame que vem sendo levantado das grandes-reportagens, bem como no estado de arte ao que compete a intervenção metodológica de análise de tais conteúdos. Constata-se uma maneira ainda tímida no sentido de apuração dos dados (nas representações de infográficos), na construção da composição destas representações, na organização das informações

O foco ilustrado é sobre visualidade da informação onde alguns autores vão defender a produção de sentidos de tais produções (em especial, infográficos) como pontos ancorados na corrente de análise do discurso. Com um movimento metodológico de adotar critérios para analisar os materiais, tais estudos tratam a imagem e texto como elementos que competem entre si, com pouca articulação, propondo uma análise meramente descritiva de um destes elementos (concentrando atenção para linhas, cores, formas etc).

Também não é o foco desses estudos a abordagem de um caráter emotivo e sensorial presentes nos materiais propostos à análise, com exceção do ano mais recente, 2018, com produções que direcionam esforços para reflexão das raízes históricas do jornalismo visual, gráfico e suas ligações com movimentos artísticos anteriores como o renascimento onde já se representava informações visualmente a 
fim de tornar compreensível o incompreensível (como exemplo, vemos Leonardo Da Vinci como um dos precursores da infografia, indicando que a infografia é muito mais do que o uso de dispositivos e representação contemporânea) (FERNANDES; BERBERT, 2018). É possível notar um cenário promissor, nesse sentido. Aponta-se para um pensamento sobre o caráter emotivo, sobre uma percepção estética e não apenas puramente retiniana, lançando, assim, um convite a se pensar sobre a integração cuidadosa dos elementos que compõem uma informação visual.

Implica dizer que há espaço para que as abordagens que se dedicam ao exame do jornalismo visual intensifiquem certas discussões interdisciplinares a respeito da relação entre imagem e texto (BARTHES, 1990, MITCHELL, 1987, 1995, 2009), do caráter lacunar da visualidade, criação de esquemas visuais e estereotipia (GOMBRICH, 1995, 2012), aprofundando tal debate. E há uma perspectiva promissora para se pensar sobre uma natureza mais imersiva, sobre as fronteiras entre a tensão teórica e prática, reflexiva e pragmática desse jornalismo visual (muito além da análise estrutural ou análise concentrada nas tecnologias para explicar os modos de informar visualmente os acontecimentos jornalísticos).

Para além de tais facetas, a fragilidade reside na escassez de estudos bibliométricos e pesquisas voltadas para as lacunas existentes nas abordagens do jornalismo visual e visualidade da informação. Essa faceta sinaliza que ainda pouco se discute sobre potencialidades e lacunas existentes em produções científicas e no horizonte teórico e metodológico das questões de visualidade da informação. É nesse sentido que o estudo presente espera fornecer bases para repertórios e reflexões, tanto para antigos quanto novos pesquisadores de modo a caminharem na inovação da pesquisa (área de ciências sociais ou outras tangenciadas).

\section{REFERÊNCIAS}

AUSSERHOFER et al. The datafication of data journalism scholarship: Focal points, methods, and research propositions for the investigation of data-intensive newswork. Journalism: UK, 2017.

BARBOSA, S.; DA SILVA, F.; NOGUIRA, L. Análise da convergência de conteúdos em produtos jornalísticos com presença multiplataforma. Revista Eletrônica do Programa de Pós-Graduação em Mídia e Cotidiano, n. 2, p. 139-162, jun. 2013.

BARROS, A. Do obstáculo especular à ilusão epistemológica na teoria da fotografia. Revista Matriz, São Paulo, v. 8, n. 1, p. 219-235, jan-jun 2014.

BARTHES, R. O Óbvio e o Obtuso. Rio de Janeiro: Nova Fronteira, 1990.

CAIRO, A. What should you show in a graphic? Some guidelines for breaking-news online infographics. Design Journal, n. 99, 2006.

CASADEI, E.; RODRIGUES, K.; BIERNATH, C. O não dito em infográficos: jornalismo de dados, discurso constituinte e silêncio como efeito de sentido. Revista de Estudos da Comunicação, v. 17, n. 43, p. 101-1007, set-dez, 2016. 
CIRNE, L. Novas imagens tecnológicas: a infografia no jornalismo. Revista Cultura Midiática, v. 3, n. 2, jul-dez, 2010.

DE PABLOS, J. Siempre ha habido infografia. Revista Latina de Comunicacion social. 1998.

DE SOUZA, J. Infográfico: modos de ver e ler ciência na mídia / Infographics: Ways of Seeing and Reading Science in Media. Bakhtiniana, São Paulo, v. 11, n. 2, p. 190-206, maio-ago, 2016.

FERNANDES, D.; BERBERT, E. Infografia: De Leonardo da Vinci à Folha de S. Paulo: os caminhos para redigir graficamente. Revista Conceitos, v. 1, n. 26, p. 24-38, jan-jun, 2018..

GOMBRICH, E. Arte e Ilusão: um estudo da psicologia da representação pictórica. São Paulo: Martins Fontes, 1995.

GOMBRICH, E. Gombrich Essencial: textos selecionados sobre arte e cultura. Porto Alegre: Bookman, 2012.

HILL, J.; SCHWARTZ, V. Getting the picture: the visual culture of the news. Londres: Bloomsbury Publishing, 2015.

JUNIOR, W.; BARBOSA, E. A infografia multimídia como narrativa jornalística e as possibilidades do HTML5. Brazilian Journalism Research, v. 2, n. 2, 2015.

MANOVICH, L. O que é visualização. (Trad.) RIBEIRO, A.E., PAIVA, F.A., ROCHA, V. Estudos em jornalismo e mídia. Florianópolis, v. 8 n. 1, p. 146-172, 2011.

MITCHELL, W. J. T. Como caçar (e ser caçado por) imagens: entrevista com W. J. T. Mitchell. Entrevista concedida a Daniel Portugal e Rose de Melo Rocha. Ecompós, Brasília, v. 12, n. 1, jan-abr., 2009.

MITCHELL, W. J. T. Iconology - Image, Text, Ideology. Chicago: The University of Chicago press, 1987.

MITCHELL, W. J. T. Picture Theory: Essays on Verbal and Visual Representation. Chicago: University of Chicago Press, 1995.

MITCHELL, W. J. T. Four fundamental concepts of image science. In: ELKINS, J. (org.). Visual literacy. New York: Routledge, 2008.

PELTZER, G. Periodismo Iconográfico. Ed. Rialp. Madrid, 1991.

RITCHIN, F. Bending the Frame: Photojournalism, Documentary, and the Citizen. New York: Aperture, 2013. 
RODRIGUES, K.; BIERNATH, C. História da infografia: da mera ilustração à valorização narrativa. In: Alcar 2015, 03-05 jun. 2015, UFRGS, Porto Alegre: Rio Grande do Sul. Anais do $10^{\circ}$ encontro nacional de história da mídia. ISSN 2175-6945.

SANCHO, J. De Pablo. Infoperiodismo. El periodista como creador de infografía. Madrid: Editorial Síntesis, 1999, 238 p.

SANCHO, J. De Pablo. La infografía: técnicas, análisis y usos periodísticos. València: Universitat de València; Castelló de la Plana: Publicaciones de la Universitt Jaune I; Barcelona: Universitat Pompeu Fabra; Bellaterra: Universitat Autónoma de Barcelona, Servei Publicacions, D.L. 2001. 